\title{
Optimization of Acid Hydrolysis Process for the Preparation Cellulose Nanofibrils
}

\author{
Melina E. Bracone, Leandro N. Ludueña*, Vera A. Alvarez
}

Consejo Nacional de Investigaciones Científicas y Técnicas (CONICET), Instituto de Investigaciones en Ciencia y Tecnología de Materiales (INTEMA), Grupo de Materiales Compuestos Termoplásticos (CoMP) Facultad de Ingeniería, Universidad Nacional de Mar del Plata, Av. Colón 10850 (B7606BVZ) Mar del Plata, Argentina

*Corresponding author: Tel: (+54) 223626 0600; E-mail: luduenaunmdp@ gmail.com

Received: 11 July 2018, Revised: 18 December 2018 and Accepted: 18 December 2018

DOI: 10.5185/amlett.2019.2182

www.vbripress.com/aml

\begin{abstract}
Cellulose nanofibrils can be obtained from microcrystalline cellulose by acid hydrolysis processes. Under optimum hydrolysis conditions is possible to obtain cellulose nanofibers with high surface / volume ratio, high aspect ratio (length to diameter), high crystallinity and improved thermal stability. All these parameters then determine their effectiveness as reinforcement in a polymer matrix. In this work, cellulose nanofibrils were obtained from commercial microcellulose supplied by Aldrich. The acid hydrolysis synthesis was optimized studying the effect of reaction time and temperature and acid solution concentration. The optimized parameters were selected so as to obtain fibers with high crystallinity, high aspect ratio with diameter in nanoscale and high thermal stability. The morphology and size (length and diameter) of the fibers was analyzed by Field Emission Scanning Electron Microscopy (FESEM), the chemical structure by Fourier Transform Infrared Spectroscopy (FTIR), thermal stability by Thermogravimetric Analysis (TGA) and crystallinity by Xray Diffraction (XRD). Copyright @ VBRI Press.
\end{abstract}

Keywords: Cellulose, nanofibrils, optimization, acid hydrolysis, characterization.

\section{Introduction}

Cellulose is the main component of several natural fibers and agricultural byproducts such as sisal, cotton, and flax fibers, corn stover and rice husk within others. The $\alpha$ cellulose percent content of these materials is $60-67,90,62-72,38-40$ and 28-36, respectively [1-3]. The structure of the natural fiber consists on cellulose, which awards the mechanical properties of the complete natural fiber, ordered in microfibers enclosed by the other two main components: hemicellulose and lignin [4]. Cellulose microfibers (CMF) can be found as intertwined microfibers in the cell wall $(2-20 \mu \mathrm{m}$ diameter and 100-40,000 $\mathrm{nm}$ long depending on its source) [5]. It is a linear polymer of $\beta-(1 \rightarrow 4)$-Dglucopyranose units. The mechanical properties of CMF depend on the cellulose polymorph present named cellulose I, II, III and IV, being type I the one showing better mechanical properties. Hemicellulose is composed of different types of cycled saccharides such as xylose, mannose and glucose, among others. It forms a highly branched random structure and it is mainly amorphous [6].

Lignins are amorphous polymers formed by phenylpropane units. They mainly consist of aromatic units such as guaiacyl, syringyl and phenylpropane [7]. There are a great number of potential uses of CMF within different industries. As a result, it has created an important focus for researcher's interest. On this field, CMF production from agro-resources has become really significant. It generally involves fibers treatment with alkalis or bisulphites to separate the lignin and to extract the hemicelluloses $[\mathbf{8}, \mathbf{9}]$.

CMF are conformed by nanocrystalline domains and amorphous cellulose regions [5]. The nanocrystalline domains are often called cellulose nanofibrils (CNF) showing diameters of 5-50 nm and lengths of several millimeters. A controlled acid hydrolysis can separate both regions driving to crystalline domains with an elastic modulus of $150 \mathrm{GPa}$, which is higher than that of the S-glass $(85 \mathrm{GPa})$ and Aramid fibers (65 GPa) [7]. In addition, it can be found in the literature [7-12] that cellulose nanofibrils have improved mechanical performances in comparison with CMF. Cellulose nanofibrils have been obtained by the acid hydrolysis of cotton [13], sisal [8] and flax fibers [14] and rice husk [15]. Corn stover has not been widely studied to obtain CNF due to its wide availability over other agricultural byproducts which make it useful for bioenergy applications such as bioethanol and biodiesel 
production [16-17]. Because of their good mechanical properties, the production of CNF has generated a great deal of interest as a source of nanometer-sized reinforcement for polymeric products. In the last years these fibers also attracted much attention due to environmental concerns especially as the reinforcement of bio-degradable polymers to produce fully biodegradable nano-composites with enhanced mechanical properties [12].

Several works have dealt with the isolation of cellulose nanofibrils from different sources by acid hydrolysis but only few of the them have deeply studied the effect of reaction conditions in order to optimize the process. In this sense, [18] have studied the effect of reaction time and sulfuric acid concentration on the morphology, crystallinity and thermal stability of CNF from bacterial cellulose at constant temperature and fiber / acid solution mass ratio [19] have obtained CNF from commercial CMF supplied by Shanhe Pharmaceutical Excipients Co., Ltd. They studied all parameters involved in the synthesis of CNF by acid hydrolysis on the morphology and chemical properties of the final fibers. Temperature, time and acid concentration were varied between $20 / 60^{\circ} \mathrm{C}, 2 / 6 \mathrm{~h}$ and $20 / 60 \mathrm{wt} . \%$, respectively. Temperature and time had not strong influence on the final properties and morphology of the fiber. Increasing acid contration from 20 to $60 \mathrm{wt} . \%$ reduced the diameter and crystallinity of the CNF [20] have optimized the acid hydrolysis parameters to obtain $\mathrm{CNF}$ from commercial CMF derived from Norway spruce (Picea abies) (Borregaard ChemCell, Sarpsborg, Norway). They found optimal hydrolysis conditions for an acid concentration of $63.5 \mathrm{wt} . \%$ and reaction time of $2 \mathrm{~h}$. They did not find strong influence of the reaction temperature in the processing window evaluated. They conclude that these optimal conditions are only applied for the cellulose source used in that work.

Strict quality control and wide availability of CMF together with optimized hydrolysis conditions are needed focusing on a final application of CNF as reinforcement of commercial products based on polymer matrices. To our knowledge this work has not been done using CMF from Sigma Aldrich as raw material.

The aim of this work was to establish a correlation between the acid hydrolysis conditions (acid concentration, time and temperature) and the final thermal stability, crystalline and chemical structure and morphology of CNF obtained from commercial CMF supplied by Sigma Aldrich.

\section{Experimental}

\section{Materials}

Commercial cellulose microfibers (CMF), from Sigma Aldrich (USA), were used as CNF source. Deionized water and Sulfuric Acid (from Cicarelli, Argentina) were used for $\mathrm{CNF}$ synthesis. All reagents used were analytical grade.

\section{Cellulose nanofibrils production}

CNF was prepared by the acid hydrolysis of CMF. The acid hydrolysis process employed consists of subjecting the CMF to a solution resulting from the mixture of deionized water and concentrated sulfuric acid under constant stirring at controlled conditions, such as acid nature, acid concentration, cellulose / solution ratio, temperature and reaction time. The acid hydrolysis was carried out with three concentrations of sulfuric acid solution: 55,60 and $65 \mathrm{w} / \mathrm{v} \%$, three temperatures: 40,45 and $50^{\circ} \mathrm{C}$ and three times: 25,30 and $35 \mathrm{~min}$. In all cases $5 \mathrm{~g}$ of CMF were dispersed in $50 \mathrm{ml}$ of each sulfuric acid solution. Seven groups of reaction parameters were used as shown in Table 1, which were designed for studying the effect of reaction time (t) and temperature $(\mathrm{T})$ and concentration of acid solution (C) on the final characteristics of CNF.

After reactions all the nanofibril dispersions were subjected to dilution by duplication of the initial volume with deionized water. Then, acid extraction was performed by dialysis against deionized water until obtaining $\mathrm{PH}=7$ in the aqueous nanofibril medium. Dialysis process involved 5 days. Finally, the water was removed by lyophilization from the suspension of cellulose nanoparticles, obtaining a powder of cellulose nanofibrils.

Table 1. Combination of parameters for acid hydrolysis optimization

\begin{tabular}{c|c|c|c}
\hline Name & $\mathrm{t}(\min )$ & $\mathrm{T}\left({ }^{\circ} \mathrm{C}\right)$ & $\mathrm{C}(\mathrm{w} / \mathrm{v} \%)$ \\
\hline $\mathrm{H} 1$ & 25 & 45 & 60 \\
\hline $\mathrm{H} 2$ & 30 & 45 & 60 \\
\hline $\mathrm{H} 3$ & 35 & 45 & 60 \\
\hline H4 & 25 & 50 & 60 \\
\hline H5 & 25 & 45 & 65 \\
\hline H6 & 25 & 45 & 55 \\
\hline H7 & 25 & 40 & 60 \\
\hline
\end{tabular}

\section{Characterization methods}

Fourier Transformed Infrared Spectroscopy (FTIR). Diffuse reflectance method (DRIFT) was followed in order to obtain FTIR spectra. 64 scans were carried out on wavenumber from 4000 to $600 \mathrm{~cm}-1$. The equipment used was a FTIR Genesis II.

X-ray Diffraction (XRD). A PW1710 Diffractometer equipped with an X-ray generator $(\lambda=0.154 \mathrm{~nm})$ was used. Powder X-Ray diffractometry was carried out. Samples were scanned in $2 \theta$ ranges varying from 5 to $40^{\circ}(1 \% \mathrm{~min})$.

Thermogravimetric Analysis (TGA). Dynamic thermogravimetric measurements were performed by using a Shimadzu TGA-DTG 50 instrument. Derivative TGA (DTGA) was performed to calculate the temperatures for the maximum thermal degradation rates of the main components in CMF and CNF. Temperature programs for dynamic tests were run from 25 to $1000{ }^{\circ} \mathrm{C}$ at a heating rate of $10 \mathrm{oC} / \mathrm{min}$ under air atmosphere $(20 \mathrm{ml} / \mathrm{min})$. All specimens were preconditioned at $65 \% \mathrm{RH}$ (relative humidity) and $20{ }^{\circ} \mathrm{C}$. 
Field Emission Scanning Electron Microscopy (FESEM). The morphology of the raw materials was analyzed by FESEM micrographs with a field emission scanning electron microscope Carl Zeiss NTS SUPRA 40. Prior to the observation, the surfaces were sputtercoated with a gold layer of about $100 \AA$ to avoid charging under the electron beam. From these images the diameter and length of the fibers were measured. A minimum of 40 fibers for each sample were measured with ImageProPlus software for the statistical analysis.

\section{Results and discussion}

\section{Cellulose microfibers (CMF) characterization}

The chemical composition of the CMF was analyzed by FTIR. The FTIR allows characterizing the chemical structure by identifying the functional groups present in each sample. The infrared spectra of hemicellulose, lignin and cellulose have been extensively reported in the literature [21-25]. The three materials are mainly composed of alkanes, esters, aromatics, ketones and alcohols, with different oxygen-containing functional groups. Changes in the chemical structure of cellulose can also be recognized by this technique. Fig. 1 shows the FTIR spectra for the CMF.

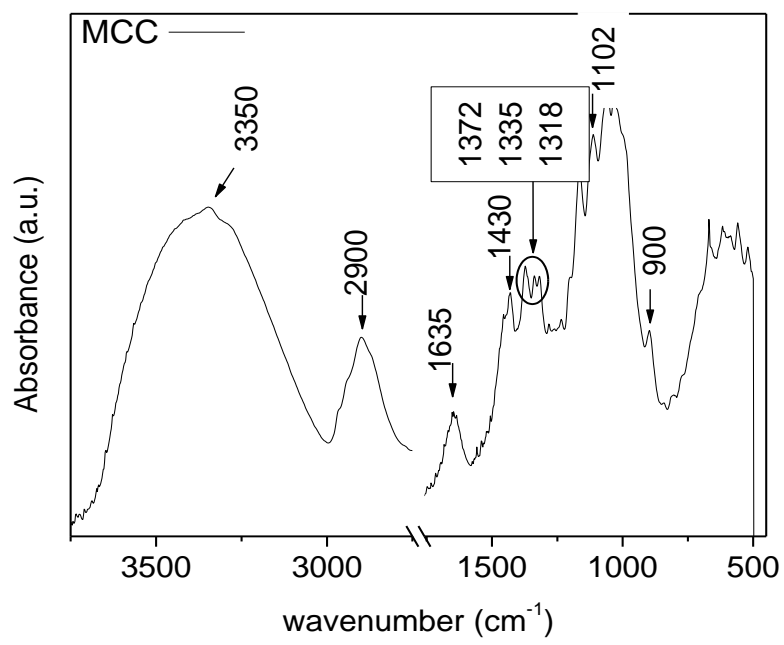

Fig. 1. FTIR spectra of cellulose microfibers.

The wavelengths for the vibration of the characteristic functional groups of cellulose are clearly identified with an arrow in the spectra.

The peak in between $3060-3640 \mathrm{~cm}-1$ is representative of the $\mathrm{C}-\mathrm{H}$ and $\mathrm{OH}$ groups. The band at $1635 \mathrm{~cm}-1$ is attributed to the $\mathrm{OH}$ bending of absorbed water. The absence of bands at $2850 \mathrm{~cm}-1$ (C-H stretching in lignin and waxes [26-27]), $1732 \mathrm{~cm}-1$ (vibrations of acetyl and uronic ester groups of hemicelluloses or ester linkage of carboxylic group of the ferulic and p-coumaric acids of lignin [28]), 1594$1509 \mathrm{~cm}-1$ (aromatic rings vibrations, lignin [29-30] $1460 \mathrm{~cm}-1$ (C-H deformations, lignin [26, 29-30]), 1235 cm-1 (guaiacyl ring breathing with stretching $\mathrm{C}=\mathrm{O}$, lignin [29-30] and $1043 \mathrm{~cm}-1$ (C-O-C stretching related with xylans associated with hemicelluloses $[31]$ in $\mathrm{CMF}$ spectra demonstrates the high purity of these fibers, since they have not residual contents of lignin, hemicellulose nor waxes. The peak at $1102 \mathrm{~cm}^{-1}$ suggests that cellulose I polymorph is present in CMF. The bands at $1430 \mathrm{~cm}^{-1}$, $1372 \mathrm{~cm}^{-1}, \quad 1335 \quad \mathrm{~cm}^{-1}$ and $1318 \mathrm{~cm}^{-1}$ occur due to $\mathrm{COH}$ and $\mathrm{HCC}$ bending vibrations and are typical of crystalline cellulose [32]. The peaks at 900 and $2900 \mathrm{~cm}^{-1}$ are related with the crystallinity and crystalline structure of CMF. It was found that thinner peaks at $900 \mathrm{~cm}^{-1}$ reflect less amorphous cellulose, while higher intensity at $900 \mathrm{~cm}^{-1}$ suggests that the crystalline structure change from cellulose I to cellulose II polymorph [33]. On the other hand, [34] have found that the band at $2900 \mathrm{~cm}^{-1}$ is sensitive to changes of the amorphous regions of cellulose.

The X-ray diffractometer was used to investigate the crystalline structure of CMF. The X-ray (XRD) curve of the CMF is shown in Fig. 2.

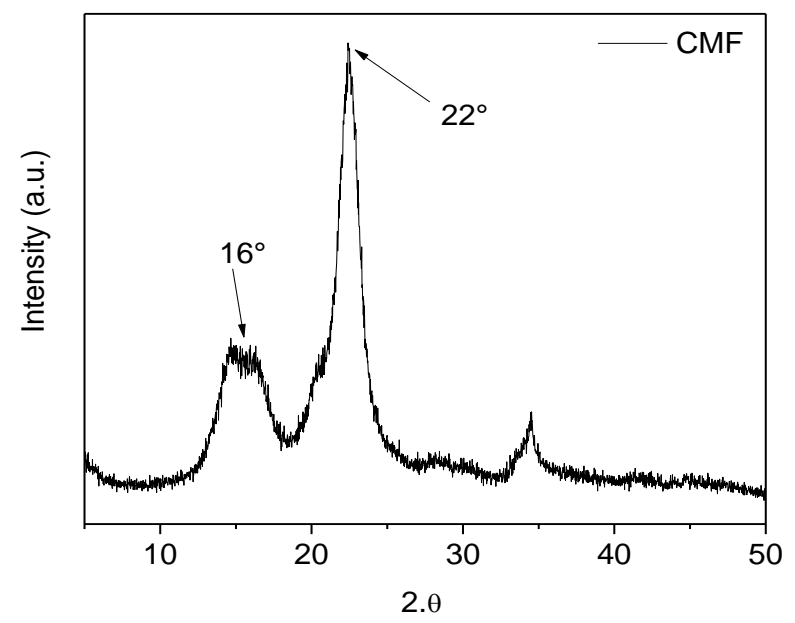

Fig. 2. XRD curve of cellulose microfibers.

The curve shows two main peaks, one close to $2 \theta=22^{\circ}$ representing the crystalline part of the materials and the other close to $2 \theta=16^{\circ}$ representing the amorphous one. The presence of only one peak close to $2 \theta=22^{\circ}$ suggests that crystalline cellulose is composed of cellulose I polymorph [36-37]. From the XRD pattern, it is possible to estimate the crystallinity index of $\mathrm{CMF}$ as follows [38]:

$$
I_{c}(\%)=\frac{\left(I_{\text {crystalline }}-I_{\text {amorphous }}\right)}{I_{\text {crystalline }}} .100
$$

where $\mathrm{I}_{\text {crystalline }}$ is the intensity at $22^{\circ}$ and $\mathrm{I}_{\text {amorphous }}$ is the intensity of the peak at $2 \theta$ angle close to $16^{\circ}$ (amorphous). The crystallinity in the CMF was $61 \%$.

The thermogravimetric analysis (TGA) allows studying the thermal stability of the materials and the derivative thermogravimetric analysis (DTGA) allows identifying the temperatures at maximum weight loss rate of the components. Fig. 3 shows the TGA and DTGA curves of CMF. Decomposition of CMF showed 2 stages. The first one corresponds to evaporation of water (small weight loss in the range $25-150^{\circ} \mathrm{C}$ ). It is 
well known that $\mathrm{CMF}$ is hydrophilic in nature. The moisture content (M) of CMF was calculated by the mass loss at $150{ }^{\circ} \mathrm{C}$ from the TGA curves resulting in $5.8 \%$. The values are in accordance with those reported in the literature [35]. The second decomposition step corresponds to pyrolysis process of cellulose. The temperature for the maximum weight loss rate (Tp1), calculated by DTGA, was found at $358{ }^{\circ} \mathrm{C}$ for $\mathrm{CMF}$.

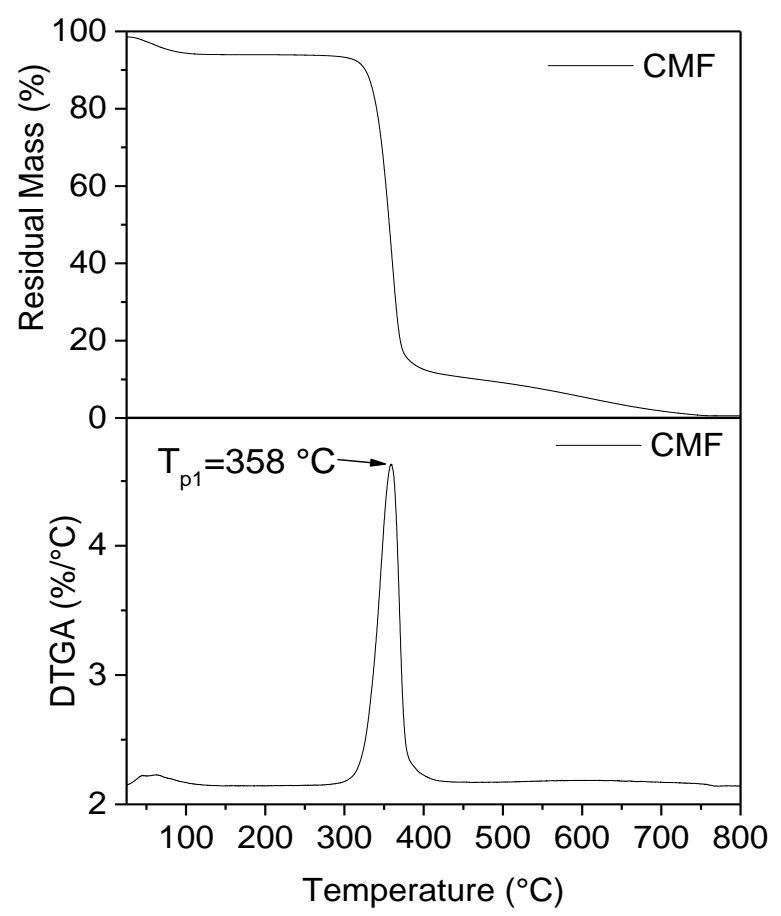

Fig. 3. TGA and DTGA curves of cellulose microfibers.

Fig. 4. shows the FESEM micrograph of CMF. Length and Diameter of at least 100 fibers were measured in order to make a statistical distribution. The CMF showed length (1) of $71084 \pm 21995 \mathrm{~nm}$ and diameter (d) of $16585 \pm 3072 \mathrm{~nm}$, resulting in an aspect ratio $(1 / \mathrm{d})$ of 4.3 .

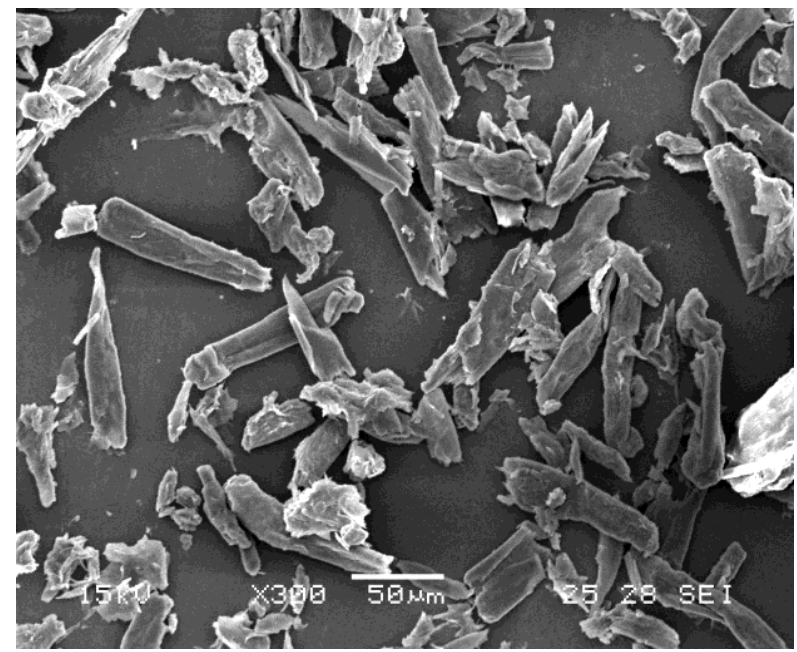

Fig. 4. FESEM micrograph of CMF.
Optimization of hydrolysis parameters for the preparation of cellulose nanofibers (CNF)

\section{Effect of hydrolysis temperature}

CNF prepared by procedures $\mathrm{H} 7, \mathrm{H} 1$ and $\mathrm{H} 4$ were submitted to the same concentration of solution $(60 \mathrm{w} / \mathrm{v} \%)$ and reaction time $(25 \mathrm{~min})$ but different temperature $\left(40,45\right.$ and $50^{\circ} \mathrm{C}$, respectively). The effect of reaction temperature on the chemical composition, crystalline structure, thermal stability and morphology of the obtained CNF will be analyzed in this section.

Fig. 5 (a, b) show the FTIR and XRD spectra of the obtained $\mathrm{CNF}$ for the different studied reaction temperatures.

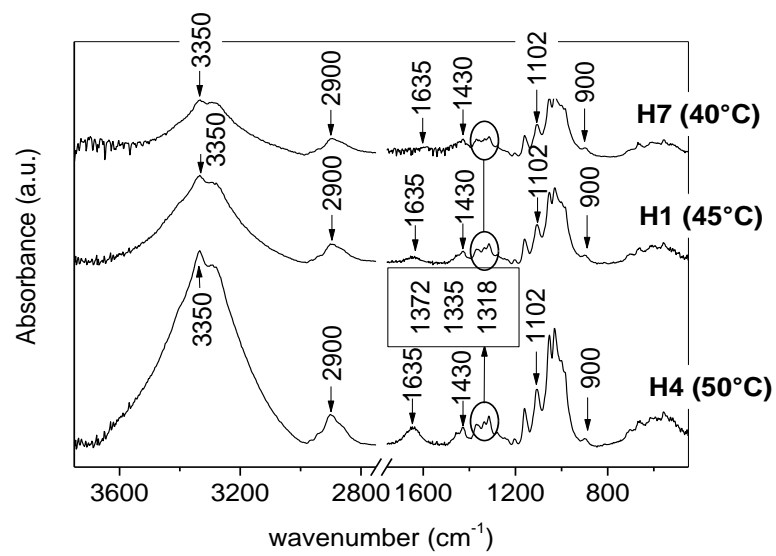

(a)

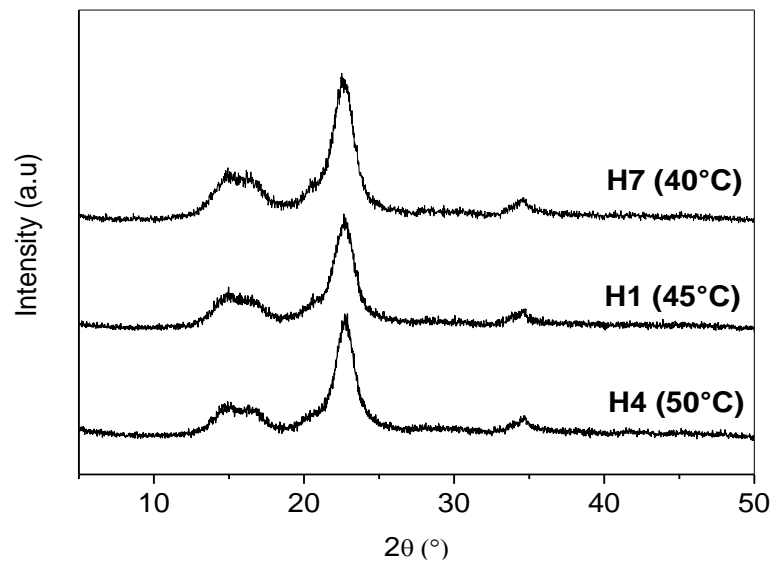

(b)

Fig. 5. Effect of reaction temperature on the FTIR (a) and XRD (b) spectra of CNF (time: $25 \mathrm{~min}$., acid concentration: $60 \mathrm{w} / \mathrm{v} \%$ ).

The FTIR spectra of CMF and CNF were normalized at the peak of $\mathrm{CH} 2(2900 \mathrm{~cm}-1)$ in order to make comparisons between them. The characteristic peaks corresponding to the vibration of the functional groups of the cellulose can be observed in Fig. 5a. All characteristic peaks of $\mathrm{CMF}$ are still present in the CNF spectra. This result suggests that the cellulose components were not degraded or removed with the acid hydrolysis. The peak at $1102 \mathrm{~cm}^{-1}$ was not significantly changed after acid hydrolysis, suggesting that cellulose I polymorph is present in both CMF and CNF. Thinner 
and less intense peak at $900 \mathrm{~cm}^{-1}$ are observed in Fig. 5a in comparison with that observed for CMF in Fig. 1. [39] shown that thinner peak at $900 \mathrm{~cm}^{-1}$ reflect less amorphous cellulose, which is expected since it is the role of the acid hydrolysis, while lower intensity at $900 \mathrm{~cm}^{-1}$ suggest the presence of cellulose I polymorph. The effect of acid hydrolysis removing amorphous cellulose is also evident from the less intense band at $2900 \mathrm{~cm}^{-1}$ in the CNF spectra [39-40]. More intense peaks at 3350,2900 and $1635 \mathrm{~cm}^{-1}$ as a function of reaction temperature were observed. It can be attributed to the digestion of crystalline domains in CNF as a consequence of the stronger hydrolysis conditions (higher temperature) [41].

Fig. 5b shows the XRD spectra of the obtained cellulose nanofibrils. The most important peaks are observed at $2 \theta=22^{\circ}$ and $16^{\circ}$ representing the crystalline and amorphous parts respectively, so it can be concluded that the crystalline integrity is maintained after the hydrolysis. The crystallinity index of these materials was calculated by equation 1 . The results are summarized in Table 2.

Table 2. Effect of reaction temperature on the crystallinity, thermal stability and morphology of CNF (time: $25 \mathrm{~min}$., acid concentration: $60 \mathrm{w} / \mathrm{v} \%)$.

\begin{tabular}{c|c|c|c|c|c|c}
\hline Sample & $\mathrm{Ic}(\%)$ & $\mathrm{T}_{\mathrm{p} 1}\left({ }^{\circ} \mathrm{C}\right)$ & $\mathrm{T}_{\mathrm{p} 2}\left({ }^{\circ} \mathrm{C}\right)$ & $1(\mathrm{~nm})$ & $\mathrm{d}(\mathrm{nm})$ & $1 / \mathrm{d}$ \\
\hline $\mathrm{CMF}$ & 61 & 358 & --- & $\begin{array}{c}71084 \pm \\
21995\end{array}$ & $\begin{array}{c}1658 \pm \\
3072\end{array}$ & 42.9 \\
\hline $\mathrm{H} 7\left(40^{\circ} \mathrm{C}\right)$ & 74 & 315 & 508 & $247 \pm 42$ & $42 \pm 6$ & 5.9 \\
\hline $\mathrm{H} 1\left(45^{\circ} \mathrm{C}\right)$ & 74 & 333 & 491 & $190 \pm 25$ & $28 \pm 3$ & 6.8 \\
\hline $\mathrm{H} 4\left(50^{\circ} \mathrm{C}\right)$ & 75 & 334 & 489 & $226 \pm 34$ & $37 \pm 11$ & 6.0 \\
\hline
\end{tabular}

The value Ic for CMF was $61 \%$ while for the CNF was between 74 and $75 \%$, which is a consequence of the removal of amorphous regions after acid hydrolysis [4243]. Crystallinity did not change as a function of reaction temperature.

Fig. 6 shows the TGA and DTGA curves of the CNF as a function of reaction temperature.

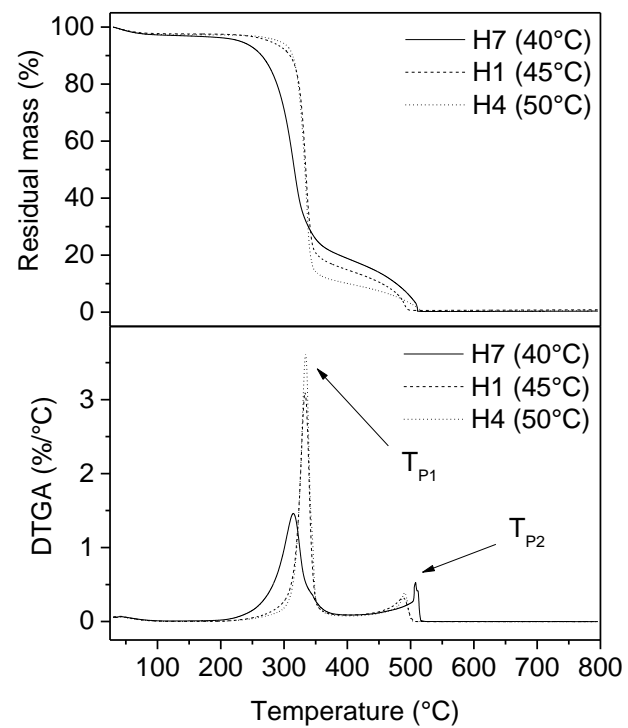

Fig. 6. Effect of reaction temperature on the TGA and DTGA curves of CNF (time: $25 \mathrm{~min}$., acid concentration: $60 \mathrm{w} / \mathrm{v} \%$ ).
In contrast with CMF, CNF samples show two main thermal degradation events. The temperatures for the maximum thermal degradation rate of these events (Tp1 and Tp2) are shown in Table 2. Roman et al. found the same behavior for sulfuric acid hydrolyzed bacterial cellulose [31]. They suggest that the process at lower temperature (Tp1) may be a consequence of the degradation of sulfated amorphous regions, whereas the higher temperature event (Tp2) was attributed to the breakdown of unsulfated crystals. Tp1 for all CNF samples was lower than for CMF. The presence of acid sulfate groups decreased the thermal stability of cellulose as a result of the dehydration reaction [44-45]. The CNF prepared at the lowest reaction temperature $\left(\mathrm{H} 7 / 40^{\circ} \mathrm{C}\right)$ showed the lowest $\mathrm{Tp} 1$ value. The improved effectiveness of $\mathrm{H} 7$ conditions removing the amorphous cellulose regions demonstrated by FTIR is also revealed by TGA since the weight loss corresponding to amorphous thermal degradation (Tp1) is lower at these conditions. In addition, more effective hydrolysis conditions become amorphous regions more susceptible to thermal degradation in the presence of sulfate groups [46]. Analyzing Tp2, higher thermal stability was observed for H7. Acid hydrolysis performed at 45 and $50^{\circ} \mathrm{C}$ showed reduced thermal stability of cellulose crystals (lower Tp2). This result may be a consequence of the weakened crystal regions due to more intense hydrolysis conditions which may be promoting the digestion of the cellulose crystal structure [18].

Figs. 7(a-c) show the effect of reaction temperature on the morphology of CNF observed by FESEM. Similar images were obtained for all hydrolysis conditions. Table 2 shows the statistical analysis of fiber length and diameter as a function of reaction temperature.

The diameter of CMF decreased after acid hydrolysis obtaining nanofibers with diameter between 27 and $42 \mathrm{~nm}$. On the other hand, the length of the fibers decreased more abruptly than its diameter in such a way that the final aspect ratio of $\mathrm{CNF}$ is $85 \%$ lower than for CMF. The effectiveness of CNF as reinforcement of a certain polymer matrix should be evaluated not only in terms of the increased surface area of the fiber but also on its aspect ratio. The statistical analysis of fiber length and diameter and the aspect ratio values shows that the optimal reaction temperature id $45^{\circ} \mathrm{C}$, which showed the lowest diameter and highest aspect ratio. Fiber agglomeration may be taking place at stronger hydrolysis conditions $\left(50{ }^{\circ} \mathrm{C}\right)$ due to the digestion of cellulose crystals, which results in the increased $\mathrm{CNF}$ length and diameter.

From this section, it can be concluded that the optimal hydrolysis temperature is that of condition $\mathrm{H} 1$ $\left(45^{\circ} \mathrm{C}\right)$ since chemical and crystalline structure are not significantly modified, thermal stability is strong enough for processing temperatures of typical polymer matrices and diameter and aspect ratio are improved (lowest diameter and highest aspect ratio) which are critical parameters focusing on reinforcement of polymer matrices. 


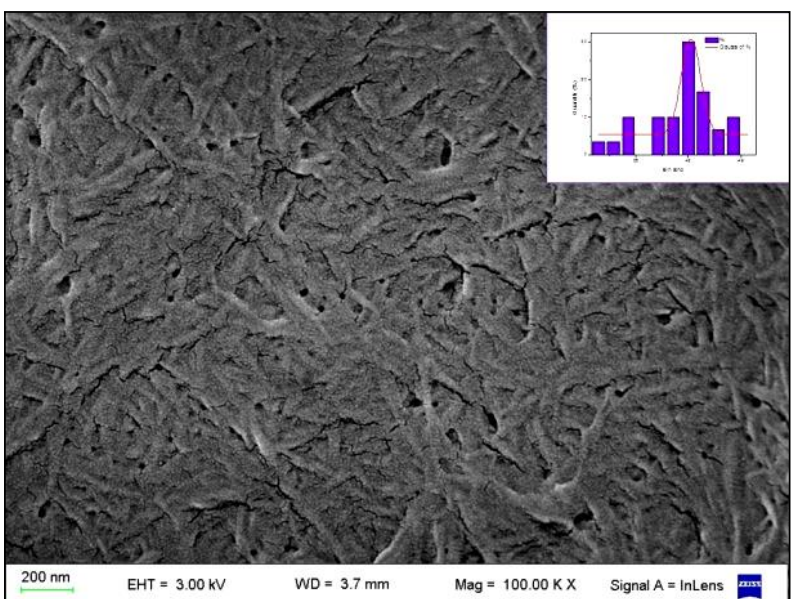

(a)

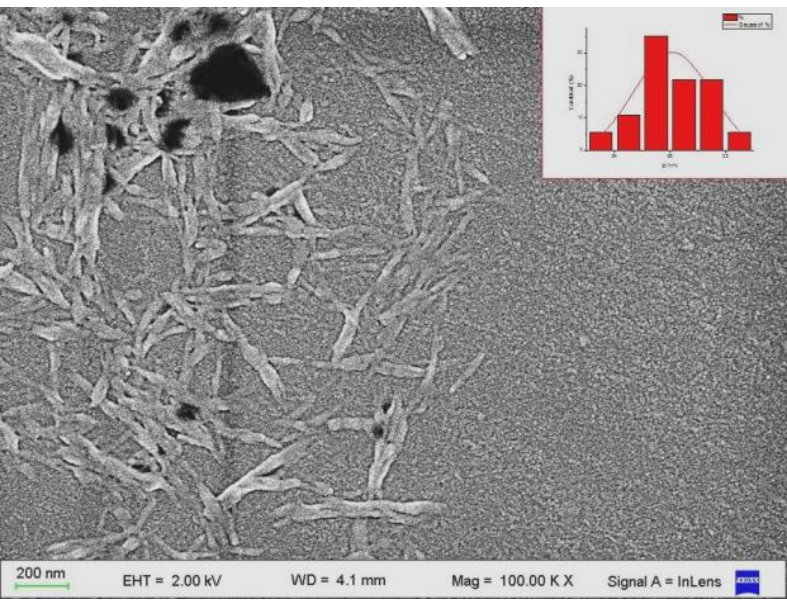

(b)

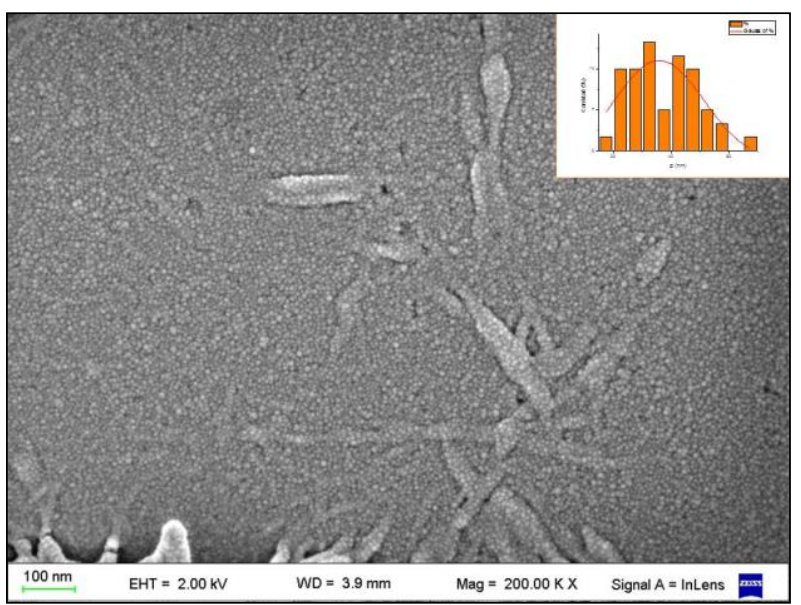

(c)

Fig. 7. FESEM micrographs of $\mathrm{CNF}$ as a function of reaction temperature (time: $25 \mathrm{~min}$., acid concentration: $60 \mathrm{w} / \mathrm{v} \%$ ): (a) $40{ }^{\circ} \mathrm{C}$; (b) $45^{\circ} \mathrm{C}$; (c) $50{ }^{\circ} \mathrm{C}$.

\section{Effect of hydrolysis time}

Samples prepared by three hydrolysis conditions (H1, H2, H3) were analyzed. Hydrolysis times were $25 \mathrm{~min}$, $30 \mathrm{~min}$ and $35 \mathrm{~min}$, respectively, while acid concentration was $60 \mathrm{w} / \mathrm{v} \%$ and reaction temperature was the optimal selected from the previous section $\left(45^{\circ} \mathrm{C}\right)$ for the three conditions.

Fig. 8(a, b) show the FTIR and XRD spectra of the $\mathrm{CNF}$ as a function of hydrolysis time.

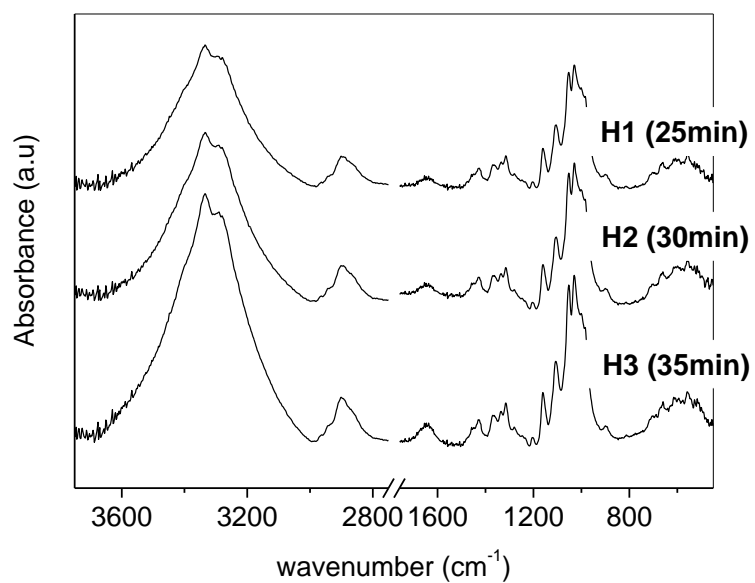

(a)

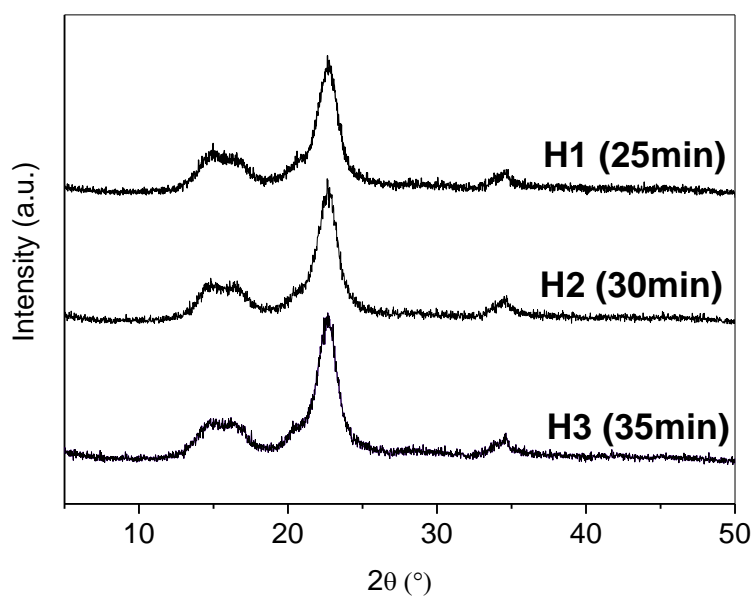

(b)

Fig. 8. Effect of hydrolysis time on the FTIR (a) and XRD (b) spectra of $\mathrm{CNF}$ (temperature: $45^{\circ} \mathrm{C}$, acid concentration: $60 \mathrm{w} / \mathrm{v} \%$ ).

All characteristic FTIR peaks of CMF are still present in the CNF spectra (Figure 8a). The same result was obtained in the previous section. In this case, the position and intensity of the peaks were not changed as a function of hydrolysis time. This result suggests that crystalline CNF regions were not damaged. It can be concluded that increasing hydrolysis time is less aggressive than increasing temperature reaction in the processing window studied.

Fig. 8b shows the XRD spectra of the obtained CNF. The most important peaks are observed at $2 \theta=22^{\circ}$ and $16^{\circ}$ representing the crystalline and amorphous parts respectively, so that the crystalline integrity can be said to be maintained after the hydrolysis. As it was previously explained, from these curves it is possible to estimate the crystallinity index of the materials according to equation (1). The results are shown in Table 3. It can be observed that 
the reaction time did not modified the crystallinity index of the CNF, which was expected from FTIR analysis.

Table 3. Effect of reaction time on the crystallinity, thermal stability and morphology of $\mathrm{CNF}$ (temperature: $45^{\circ} \mathrm{C}$, acid concentration: $60 \mathrm{w} / \mathrm{v} \%)$.

\begin{tabular}{c|c|c|c|c|c|c}
\hline Sample & $\begin{array}{c}\mathrm{Ic} \\
(\%)\end{array}$ & $\begin{array}{c}\mathrm{Tp} 1 \\
\left({ }^{\circ} \mathrm{C}\right)\end{array}$ & $\begin{array}{c}\mathrm{Tp} 2 \\
\left({ }^{\circ} \mathrm{C}\right)\end{array}$ & $\begin{array}{c}1 \\
(\mathrm{~nm})\end{array}$ & $\begin{array}{c}\mathrm{d} \\
(\mathrm{nm})\end{array}$ & $1 / \mathrm{d}$ \\
\hline $\mathrm{CMF}$ & 61 & 358 & --- & $\begin{array}{c}71084 \pm \\
21995\end{array}$ & $\begin{array}{c}1658 \pm \\
3072\end{array}$ & 42.9 \\
\hline $\begin{array}{c}\mathrm{H} 1 \\
(25 \mathrm{~min})\end{array}$ & 74 & 333 & 491 & $190 \pm 25$ & $28 \pm 3$ & 6.8 \\
\hline $\begin{array}{c}\mathrm{H} 2 \\
(30 \mathrm{~min})\end{array}$ & 73 & 336 & 495 & $217 \pm 32$ & $43 \pm 8$ & 5.0 \\
\hline $\begin{array}{c}\mathrm{H} 3 \\
(35 \mathrm{~min})\end{array}$ & 75 & 334 & 492 & $275 \pm 52$ & $54 \pm 8$ & 5.1 \\
\hline
\end{tabular}

Fig. 9 shows the TGA and DTGA curves of the CNF as a function of reaction time. Both TGA and DTGA curves are almost overlapped in all the temperature range. Increasing hydrolysis time did not change any parameter regarding the thermal stability of the CNF.

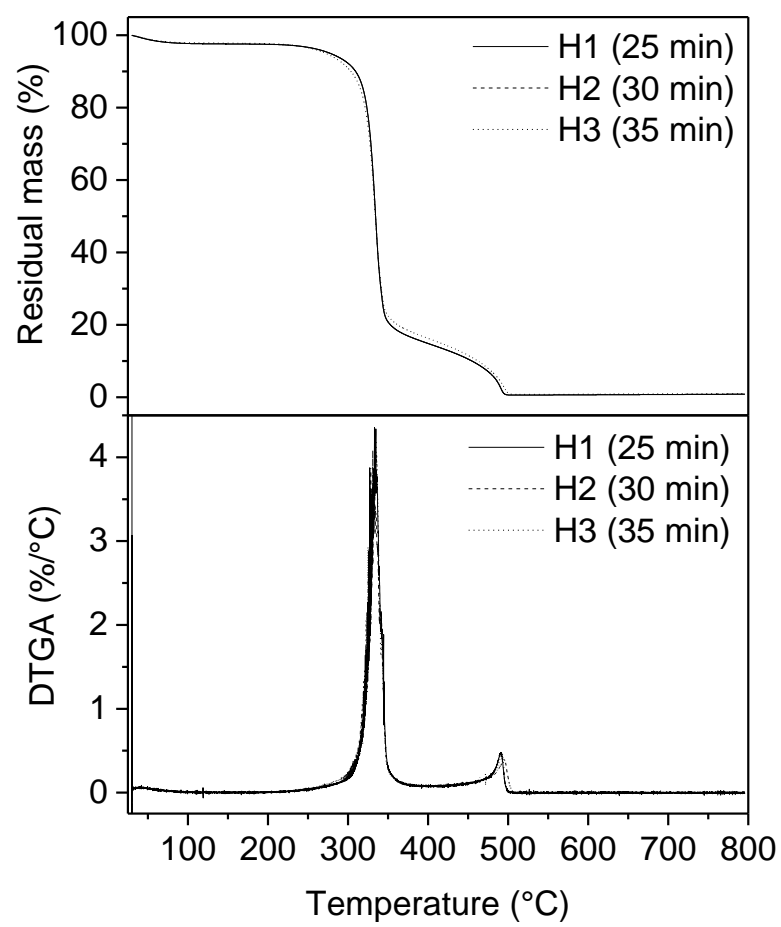

Fig. 9. Effect of reaction time on the TGA and DTGA curves of CNF (temperature: $45^{\circ} \mathrm{C}$, acid concentration: $60 \mathrm{w} / \mathrm{v} \%$ ).

From FESEM images the statistical analysis of CNF diameter and length as a function of reaction temperature was done. Table 3 shows the results. Both diameter and length of the fibers increased while its aspect ratio decreased as a function of hydrolysis time which may be attributed to a partial re-agglomeration.

From this section it can be concluded that the optimal hydrolysis time is that of condition $\mathrm{H} 1$ (25min) since higher times did not alter the chemical and crystalline structure nor thermal stability of CNF but increased length and diameter and decreased aspect ratio of the fibers which is not desirable focusing on reinforcement of polymer matrices. In addition, lower hydrolysis times are beneficial from the economical point of view focusing on industrial applications.

\section{Effect of the concentration of the acid solution}

Samples prepared by three hydrolysis conditions (H6, H1, H5) were analyzed. Acid concentrations were $55 \mathrm{w} / \mathrm{v} \%, 60 \mathrm{w} / \mathrm{v} \%$ and $65 \mathrm{w} / \mathrm{v} \%$, respectively, while reaction temperature and time were those optimized in the previous sections $\left(45^{\circ} \mathrm{C}\right.$ and $\left.25 \mathrm{~min}\right)$ for the three hydrolysis conditions.

Figs. 10(a, b) show the FTIR and XRD spectra of $\mathrm{CNF}$ as a function of acid concentration.

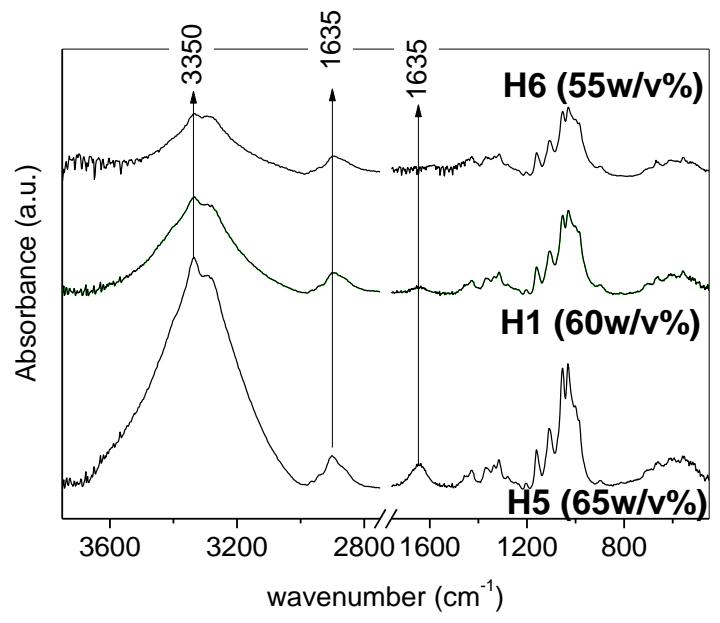

(a)

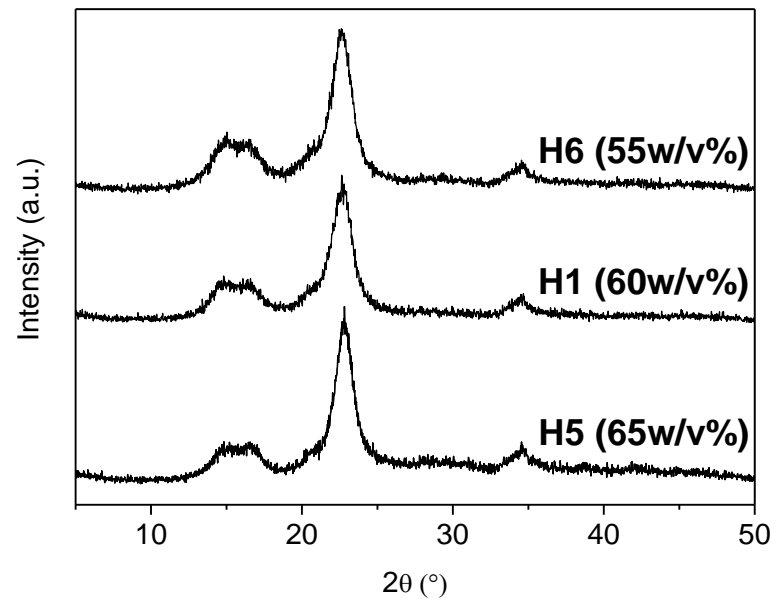

(b)

Fig. 10. Effect of acid concentration on the FTIR (a) and XRD (b) spectra of $\mathrm{CNF}$ (temperature: $45^{\circ} \mathrm{C}$, time: $25 \mathrm{~min}$.).

Regarding FTIR, same tendencies as those observed for the effect of hydrolysis temperature in Fig. 5a were observed. More intense peaks at 3350, 2900 and $1635 \mathrm{~cm}^{-1}$ as a function of acid concentration were obtained. As was previously explained, it can be attributed to the digestion of crystalline domains in CNF as a consequence of the stronger hydrolysis conditions (in this case higher acid concentration) [41]. 
Fig. 10b shows the XRD spectra of the obtained $\mathrm{CNF}$ as a function of acid concentration. The peaks at $2 \theta=22^{\circ}$ and $16^{\circ}$ are present representing the crystalline and amorphous parts of CNF. This result suggests that the crystalline integrity of cellulose is maintained after the hydrolysis. The crystallinity index was calculated by equation 1 . The results are summarized in Table 4 . The results show an increased crystallinity as a function of acid concentration which can be attributed to the stronger hydrolysis conditions which increases the effectiveness removing amorphous regions.

Table 4. Effect of acid concentration on the crystallinity, thermal stability and morphology of CNF (temperature: $45^{\circ} \mathrm{C}$, time: $25 \mathrm{~min}$.).

\begin{tabular}{c|c|c|c|c|c|c}
\hline Sample & $\begin{array}{c}\mathrm{Ic} \\
(\%)\end{array}$ & $\begin{array}{c}\mathrm{T}_{\mathrm{p} 1} \\
\left({ }^{\circ} \mathrm{C}\right)\end{array}$ & $\begin{array}{c}\mathrm{T}_{\mathrm{p} 2} \\
\left({ }^{\circ} \mathrm{C}\right)\end{array}$ & $\begin{array}{c}1 \\
(\mathrm{~nm})\end{array}$ & $\begin{array}{c}\mathrm{d} \\
(\mathrm{nm})\end{array}$ & $1 / \mathrm{d}$ \\
\hline $\mathrm{CMF}$ & 61 & 358 & --- & $\begin{array}{c}71084 \pm \\
21995\end{array}$ & $\begin{array}{c}1658 \pm \\
3072\end{array}$ & 42.9 \\
\hline $\begin{array}{c}\mathrm{H} 6 \\
(55 \mathrm{w} / \mathrm{v} \%)\end{array}$ & 68 & 342 & 503 & $229 \pm 41$ & $33 \pm 4$ & 6.8 \\
\hline $\begin{array}{c}\mathrm{H} 1 \\
(60 \mathrm{w} / \mathrm{v} \%)\end{array}$ & 74 & 333 & 491 & $190 \pm 25$ & $29 \pm 3$ & 6.8 \\
\hline $\begin{array}{c}\mathrm{H} 5 \\
(65 \mathrm{w} / \mathrm{v} \%)\end{array}$ & 78 & 334 & 507 & $250 \pm 72$ & $48 \pm 6$ & 5.2 \\
\hline
\end{tabular}

Fig. 11 shows the TGA and DTGA curves of the $\mathrm{CNF}$ as a function of acid concentration.

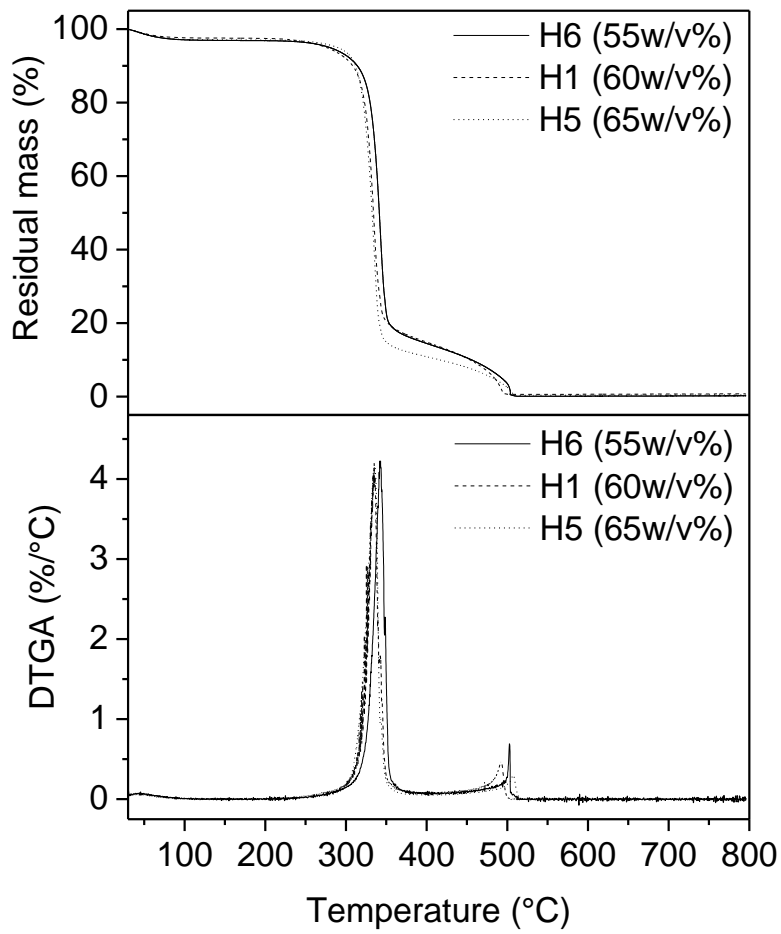

Fig. 11. Effect of acid concentration on the TGA and DTGA curves of $\mathrm{CNF}$ (temperature: $45^{\circ} \mathrm{C}$, time: $25 \mathrm{~min}$.).

Lower Tp1 as a function of acid concentration was observed [31] demonstrated that the thermal degradation of cellulose crystals containing sulphate groups occurs at lower temperatures. They stated that the thermal degradation reactions of bacterial cellulose are catalyzed by sulfuric acid. Catalysis could either be direct through the acid molecules or indirect by promoting dehydration reactions and increasing the amount of water released. The replacement of $\mathrm{OH}$ groups by sulphate groups decreases the activation energy of cellulose chain degradation. These effects are stronger as a function of acid concentration.

Table 4 also shows the statistical analysis of fiber length and diameter and aspect ratio of the CNF. Lowest diameter and highest aspect ratio were observed for the fibers prepared by the condition $\mathrm{H} 1(60 \mathrm{w} / \mathrm{v} \%)$. CNF with higher diameter and lower aspect ratio were obtained with acid concentration out of $60 \mathrm{w} / \mathrm{v} \%$. Lower acid concentration can be hydrolysis not strong enough for the optimal removal of amorphous domains, while higher acid concentration may be promoting the digestion of CNF crystalline domains [18] causing partial re/agglomeration of CNF.

Chemical and crystalline structures were not modified as a function of acid concentration. Crystallinity, diameter and aspect ratio were improved with condition $\mathrm{H} 1$. The latter parameters are considered relevant focusing on $\mathrm{CNF}$ as polymer reinforcement. For this reason, $60 \mathrm{w} / \mathrm{v} \%$ (H1 condition) is considered the optimal hydrolysis condition of this section.

\section{Conclusion}

Cellulose nanofibrils were prepared by acid hydrolysis. The effect of reaction time and temperature and acid concentration on the chemical and crystalline structure, thermal stability and fiber morphology was analyzed. High cellulose purity, crystallinity, thermal stability and aspect ratio and low diameter were the parameters to be optimized for selecting the hydrolysis conditions focusing on polymer reinforcement as the final application of the obtained CNF. Strong acid hydrolysis conditions performed by increasing reaction time, temperature and acid concentration conducted to fibers with higher diameter and lower aspect ratio, which was attributed to partial re/agglomeration of the fibers due to the digestion of crystalline domains. In some cases, the reaction conditions were not strong enough for the optimal removal of amorphous regions also leading to fiber with higher diameter and aspect ratio and lower crystallinity. Optimal hydrolysis conditions were those performed with an acid concentration of $60 \mathrm{w} / \mathrm{v} \%$ and temperature of $45^{\circ} \mathrm{C}$ for $25 \mathrm{~min}$.

\section{Acknowledgements}

Authors acknowledge the financial support of "Consejo Nacional de Investigaciones Científicas y Técnicas (CONICET)" (PIP 00617) and "Agencia Nacional de Promoción Científica Tecnológica (ANPCyT)" (FS Nano 004).

\section{References}


1. Satyanarayana, K. G.; Arizaga, G. G. C.; Wypych, F.; Prog. Polym. Sci., 2009, 34, 982.

2. Kurakake, M.; Kisaka, W.; Ouchi, K.; Komaki, T.; Appl. Biochem. Biotechnol., 2001, 90, 251.

3. Reddy, N.; Yang, Y.; Trends in Biotechnology, 2005, 23, 22.

4. Placet, V.; Compos. Part-A: Appl. S., 2009, 40, 1111.

5. Itoh, T.; Brown, R. M.; Planta, 1984, 160, 372.

6. Xiao, B.; Sun, X. F.; Sun, R.; Polym. Degrad. Stab., 2001, 74, 307.

7. Baillie, C.; Green Composites: Polymer Composites and the Environment (D. T. Nishino Ed.); in Abington Hall, Abington Cambridge CB1 6AH, England, Woodhead Publishing Limited: Department of Chemical Science and Engineering, Faculty of Engineering, Kobe University, 2004, p.49.

8. Morán, J.; Alvarez, V.; Cyras, V.; Vázquez, A.; Cellulose, 2008, $15,149$.

9. Elanthikkal, S.; Gopalakrishnapanicker, U.; Varghese, S.; Guthrie, J. T.; Carbohyd. Polym., 2010, 80, 852.

10. Petersson, L.; Oksman, K.; Compos. Sci. Technol., 2006, 66, 2187.

11. Chen, Y.; Liu, C.; Chang, P. R.; Cao, X.; Anderson, D. P.; Carbohyd. Polym., 2009, 76, 607.

12. Azizi Samir, M. A. S.; Alloin, F.; Dufresne, A.; Biomacromolecules, 2005, 6, 612.

13. De Morais Teixeira, E.; Corrêa, A.; Manzoli, A.; De Lima Leite, F.; De Oliveira, C.; Mattoso, L.; Cellulose, 2010, 17, 595.

14. Qua, E. H.; Hornsby, P. R.; Plastics, Rubber and Composites, 2011, 40,300.

15. Rosa, S. M. L.; Rehman, N.; De Miranda, M. I. G.; Nachtigall, S. M. B.; Bica, C. I. D.; Carbohyd. Polym., 2012, 87, 1131.

16. Kadam, K. L.; McMillan, J. D.; Bioresource Technology, 2003, 88, 17.

17. Sokhansanj, S.; Turhollow, A.; Cushman, J.; Cundiff, J.; Biomass and Bioenergy, 2002, 23, 347.

18. Martínez-Sanz, M.; Lopez-Rubio, A.; Lagaron, Jose M.; Carbohydrate Polymers, 2011, 85, 228.

19. Pan, M.; Zhou, X., Chen, M.; Bioresources, 2013, 8, 933.

20. Bondeson, D.; Aji, M.; Kristiina, O.; Cellulose, 2006, 13, 171.

21. Gañán, P.; Cruz, J.; Garbizu, S.; Arbelaiz, A.; Mondragon, I.; J. Appl. Polym. Sci., 2004, 94, 1489.

22. Gañán, P.; Zuluaga, R.; Velez, J.M.; Mondragon, I.; Macromol. Biosci., 2004, 4, 978.

23. Zuluaga, R.; Putaux, J. L.; Cruz, J.; Vélez, J.; Mondragon, I.; Gañán, P.; Carbohydr. Polym., 2009, 76, 51.

24. Sun, J.X.; Sun, X.F.; Zhao, H.; Sun, R.C.; Polym. Degrad. Stab., 2004, 84, 331.

25. Xu, F.; Sun, J.X.; Geng, Z.C.; Liu, C.F.; Ren, J.L.; Sun, R.C.; Fowler, P.; Baird, M.S.; Carbohydr. Polym., 2007, 67, 56.

26. Wang, N.; Ding, E.; Cheng, R.; Polymer, 2007, 48, 3486.

27. Mohanty, A.K.; Misra, M.; Hinrichsen, G.; Macromol. Mater. Eng. 2000, 1, 276

28. Sun, J.X.; Sun, X.F.; Zhao, H.; Sun, R.C.; Polym. Degrad. Stab., $\mathbf{2 0 0 4}, 84,331$.

29. Mohanty, A. K.; Misra, M.; Hinrichsen, G.; Macromol. Mater. Eng., 2000, 1, 276.

30. Ludueña, L.; Vázquez, A.; Alvarez, V.; Carbohydr. Polym., 2012, 87, 411.

31. Roman, M.; Winter, W.T.; Biomacromolecules, 2004, 5, 1671.

32. Xu, F.; Sun, J.X.; Geng, Z.C.; Liu, C.F.; Ren, J.L.; Sun, R.C.; Fowler, P.; Baird, M.S.; Carbohydr. Polym., 2007, 67, 56.

33. Kavkler, K.; Gunde-Cimerman, N.; Zalar, P.; Demšar, A.; Polym. Degrad. Stab., 2011, 96, 574.

34. Oh et al. Oh, S. Y.; Yoo, D. I.; Shin, Y.; Seo, G.; Carbohyd. Res., 2005, 340, 417.

35. Wang, N.; Ding, E.; Cheng, R.; Polymer, 2007, 48, 3486.

36. Kavkler, K.; Gunde-Cimerman, N.; Zalar, P.; Demšar, A.; Polym. Degrad. Stab., 2011, 96, 574.

37. Yang, L.; Zhang, H.Y.; Yang, Q.; Lu, D.N.; J. Appl. Polym. Sci., 2012, 126, 244.

38. Ali, M.; Emsley, A. M.; Herman, H.; Heywood, R. J.; Polymer, 2001, 42, 2893.

39. Kavkler, K.; Gunde-Cimerman, N.; Zalar, P.; Demšar, A.; Polym. Degrad. Stab., 2011, 96, 574.
40. Oh, S.Y.; Yoo, D.I.; Shin, Y.; Seo, G.; Carbohydr. Res., 2005, 340, 417.

41. Martínez-Sanz, M; Lopez-Rubio, A.; Lagaron, J.M.; Carbohydr. Polym., 2011, 85, 228.

42. Hammad, W.Y.; Hu, T.Q.; Can. J. Chem. Eng., 2010, 88, 392.

43. Li, W.; Wang, R.; Liu, S.; Bioresources, 2011, 6, 4271.

44. Fahma, F.; Iwamoto, S; Hori, N.; Iwata, T.; Takemura, A.; Cellulose, 2010, 17, 977.

45. Roman, M.; Winter, W.T.; Biomacromolecules, 2004, 5, 1048.

46. Kargarzadeh, H.; Ahmad, I.; Abdullah, I.; Dufresne, A.; Zainudin, S.I. Rasha M. Sheltami; Cellulose, 2012, 19, 855. 